\title{
Inhibition of Pseudomonas aeruginosa from cystic fibrosis by selective media
}

\author{
K FONSECA,* JANE MACDOUGALL, $\dagger$ TL PITT $\dagger$ \\ From the *Department of Microbiology, Wexham Park Hospital, Slough, and the †Division of Hospital \\ Infection, Central Public Health Laboratory, London
}

Summary Pseudomonas Isolation Agar (selective agent, Irgasan, $25 \mathrm{mg} / \mathrm{l}$ ) and Pseudomonas Selective Agar (selective agents, cetrimide $200 \mathrm{mg} / \mathrm{l}$ and nalidixic acid $15 \mathrm{mg} / \mathrm{l}$ ) inhibited some strains of $P$ aeruginosa from cystic fibrosis sputum but did not inhibit isolates from other sources. Of 200 cystic fibrosis isolates, 22 were inhibited by $16 \mathrm{mg} / 1 \mathrm{Irgasan}, 45$ by $8 \mathrm{mg} / \mathrm{l}$ nalidixic acid, and 15 by $128 \mathrm{mg} / 1$ cetrimide. We recommend that cystic fibrosis sputum should be cultured on selective and non-selective media to maximise the isolation of Paeruginosa.

Pseudomonas aeruginosa is commonly isolated from the sputum of patients with cystic fibrosis, and colonisation is often associated with a poor prognosis and increased morbidity and mortality. ${ }^{1}$ It is desirable and necessary to maximise the rate of isolation of $P$ aeruginosa from these patients, especially during the monitoring of treatment with antibiotics.

During a longitudinal study of the bacterial flora of the sputum of patients with cystic fibrosis we became aware of a decrease in the isolation rate of $P$ aeruginosa after the introduction of a selective agar for the recognition of this species. We determined, therefore, the minimum inhibitory concentrations of the selective agents Irgasan, nalidixic acid, and cetrimide in two proprietary media for strains of $P$ aeruginosa from cystic fibrosis sources and noncystic fibrosis sources and compared the viable counts of some strains on selective and non-selective agar media.

\section{Material and methods}

\section{CULTURES}

Two hundred cultures of Paeruginosa were isolated on the non-selective medium from multiple specimens of sputum from 80 patients with cystic fibrosis attending an outpatient clinic. One hundred non-cystic fibrosis cultures were selected from routine clinical isolates submitted to the Division of Hospital Infection for typing. $P$ aeruginosa NCTC10662 was used as a control for minimum inhibitory concentration determinations.

Accepted for publication 16 September 1985
MEDIA

Pseudomonas Isolation Agar (PIA, Difco, London) containing the selective agent Irgasan at $25 \mathrm{mg} / \mathrm{l}$ and Pseudomonas Selective Agar (PSA, Oxoid Ltd, Basingstoke) containing nalidixic acid and cetrimide at concentrations of $15 \mathrm{mg} / \mathrm{l}$ and $200 \mathrm{mg} / \mathrm{l}$, respectively, were prepared according to manufacturer's instructions. King's "A" agar ${ }^{2}$ was used as a nonselective control. Broth was tryptone soy broth (TSB, Oxoid).

\section{SPUTUM SPECIMENS}

Sputum samples were digested by pancreatin enzyme (BDH, Poole, Dorset) at $37^{\circ} \mathrm{C}$ for two hours ${ }^{3}$ and plated on selective and non-selective agar. Plates were incubated at $37^{\circ} \mathrm{C}$ for 48 hours, and the growth was scored semiquantitatively.

\section{MINIMUM INHIBITORY CONCENTRATION DETERMINATION}

Irgasan BP 300 (Ciba-Geigy, Horsham) and nalidixic acid (Sterling Winthrop, London) were kindly provided by the manufacturers. Cetrimide was cetyltrimethylammonium bromide (BDH, Poole). Minimum inhibitory concentration determinations were performed by an agar dilution method ${ }^{4}$ in tryptone soy agar (Oxoid). Overnight tryptone soy broth cultures of bacteria were diluted in quarter strength Ringer solution (Oxoid) to give a suspension containing about $10^{4}$ bacteria $/ \mathrm{ml}$. Diluted cultures $(30 \mu \mathrm{l}$ volumes) were applied with a multipoint inoculator (Denley Instruments Ltd, Sussex) to agar plates that contained various concentrations of the selective agents. Plates were incubated at $37^{\circ} \mathrm{C}$ for 18 hours, examined, and then reincubated for a further 24 
hours to detect slow growing colonies. The minimum inhibitory concentration was taken as the lowest concentration of the agent to inhibit the growth of the culture after 48 hours. Surface viable counts were performed by a standard method. ${ }^{5}$

\section{Results}

During the processing of the infected sputum samples we found that the selective medium in routine use, Pseudomonas Isolation Agar, inhibited some strains of $P$ aeruginosa. To confirm this observation $132 \mathrm{spu}-$ tum samples were plated both on King's " $A$ " agar and Pseudomonas Isolation Agar, and 102 of these yielded $P$ aeruginosa in pure or mixed culture; 12 specimens gave no bacterial growth on either medium. The growth of $43(42.2 \%)$ of the $P$ aeruginosa cultures was reduced on Pseudomonas Isolation Agar when compared with that on the nonselective agar. The remaining 59 cultures gave similar quantities of growth on both media. We decided, therefore, to investigate the antipseudomonas activity of the active agents both in Pseudomonas Isolation Agar and Pseudomonas Selective Agar, another widely used selective medium for $P$ aeruginosa.

The minimum inhibitory concentration of the three selective agents for 200 cystic fibrosis cultures of sputum and 100 non-cystic fibrosis cultures was determined. Table 1 shows the cumulative percentages of cultures inhibited by each agent. There was an appreciable contrast between the two groups of cultures in their sensitivity to Irgasan. All but one of the noncystic fibrosis isolates grew on agar containing
$1024 \mathrm{mg} / 1$ Irgasan while those from cystic fibrosis patients varied in their sensitivity to this compound. To come close to the concentration of Irgasan in Pseudomonas Isolation Agar $32 \mathrm{mg} / 1$ was chosen as the breakpoint concentration of Irgasan for the differentiation of resistant and sensitive cultures. Similarly, the breakpoint concentration chosen for nalidixic acid was $16 \mathrm{mg} / \mathrm{l}$ and $256 \mathrm{mg} / 1$ for cetrimide. Using these breakpoints, $18 \%$ of cystic fibrosis cultures were sensitive to Irgasan, $34 \%$ to nalidixic acid, and $9 \%$ to cetrimide.

Table 2 shows the degree of cross sensitivity of cystic fibrosis cultures to the three agents. Of 36 cultures sensitive to Irgasan, 27 and 10 were also sensitive to nalidixic acid and cetrimide, respectively. About half (33 of 68) of the cultures sensitive to nalidixic acid were inhibited by Irgasan at the breakpoint concentration, and 11 of the 18 cultures sensitive to cetrimide were sensitive to both Irgasan and nalidixic acid.

Sensitivity of cystic fibrosis isolates to Irgasan and cetrimide was significantly associated with the production of mucoid colonies on King's " $A$ " agar as 25 of $36(69 \%)(0.02>p>0.01)$ cultures sensitive to Irgasan and 13 of $18(72 \%)$ of cultures sensitive to cetrimide were mucoid. In contrast, only 16 of 68 $(23.5 \%, p<0.001)$ of cultures inhibited by $16 \mathrm{mg} / \mathrm{l}$ nalidixic acid produced mucoid colonies.

To assess the effect of the selective agents on the growth of Paeruginosa on the proprietary media viable counts of 10 cultures, which had a minimum inhibitory concentration for Irgasan of $4 \mathrm{mg} / 1$ to $32 \mathrm{mg} / \mathrm{l}$, were performed on Pseudomonas Isolation Agar. Similarly, 10 cultures with various minimum

Table 1 Inhibition of cultures of $P$ aeruginosa from cystic fibrosis and non-cystic fibrosis sources by Irgasan, cetrimide, and nalidixic acid

\begin{tabular}{|c|c|c|c|c|c|c|c|c|c|c|c|}
\hline \multirow[t]{2}{*}{ Agent } & \multirow[t]{2}{*}{ Source } & \multirow{2}{*}{$\begin{array}{l}\text { No of } \\
\text { cultures }\end{array}$} & \multicolumn{9}{|c|}{ Cumulative percentage of cultures inhibited by agent (mg/l) } \\
\hline & & & 1024 & 512 & 256 & 128 & 64 & 32 & 16 & 8 & 4 \\
\hline $\begin{array}{l}\text { Irgasan } \\
\text { Nalidixic acid } \\
\text { Cetrimide }\end{array}$ & $\begin{array}{l}\text { Cystic fibrosis } \\
\text { Non-cystic fibrosis } \\
\text { Cystic fibrosis } \\
\text { Non-cystic fibrosis } \\
\text { Cystic fibrosis } \\
\text { Non-cystic fibrosis }\end{array}$ & $\begin{array}{l}200 \\
100 \\
200 \\
100 \\
200 \\
100\end{array}$ & $\begin{array}{l}100 \cdot 0 \\
100 \cdot 0 \\
100 \cdot 0 \\
100 \cdot 0 \\
100 \cdot 0 \\
100 \cdot 0\end{array}$ & $\begin{array}{r}33 \cdot 0 \\
1.0 \\
99 \cdot 5 \\
98 \cdot 0 \\
17 \cdot 5 \\
13.0\end{array}$ & $\begin{array}{r}31 \cdot 5 \\
1 \cdot 0 \\
98 \cdot 0 \\
97 \cdot 0 \\
9 \cdot 0 \\
0 \cdot 0\end{array}$ & $\begin{array}{r}29.0 \\
1.0 \\
94.0 \\
94.0 \\
7.5 \\
0.0\end{array}$ & $\begin{array}{r}24.5 \\
1.0 \\
82.5 \\
83.0 \\
5.0 \\
0.0\end{array}$ & $\begin{array}{r}18 \cdot 0 \\
1.0 \\
56 \cdot 5 \\
42.0 \\
2.0 \\
0.0\end{array}$ & $\begin{array}{r}11.0 \\
0.0 \\
34.0 \\
1.0 \\
2.0 \\
0.0\end{array}$ & $\begin{array}{c}5 \cdot 0 \\
0.0 \\
22 \cdot 5 \\
0.0 \\
2 \cdot 0^{*} \\
0.0\end{array}$ & $\begin{array}{r}3.0 \\
0.0 \\
15.0 \\
0.0\end{array}$ \\
\hline
\end{tabular}

"Strains with minimum inhibitory concentration $\leqslant 8 \mathrm{mg} / \mathrm{l}$

Table 2 Cross sensitivity of $P$ aeruginosa isolated from cystic fibrosis to Irgasan, cetrimide, and nalidixic acid

\begin{tabular}{lllll}
\hline Agent (breakpoint) & $\begin{array}{l}\text { No of } \\
\text { cultures }\end{array}$ & \multicolumn{2}{l}{ No of cultures sensitive to: } & Cetrimide \\
\cline { 2 - 5 } & & Irgasan & Nalidixic acid & 10 \\
\hline Irgasan $(\leqslant 32 \mathrm{mg} / \mathrm{l})$ & 36 & 36 & 27 & 8 \\
Nalidixic acid $(\leqslant 16 \mathrm{mg} / \mathrm{l})$ & 68 & 33 & 68 & 18 \\
Cetrimide $(\leqslant 256 \mathrm{mg} / \mathrm{l})$ & 18 & 11 & 11 & 18 \\
\hline
\end{tabular}


inhibitory concentrations for nalidixic acid $(2 \mathrm{mg} / \mathrm{l}$ to $32 \mathrm{mg} / \mathrm{l})$ and cetrimide $(64 \mathrm{mg} / \mathrm{l}$ to $1024 \mathrm{mg} / \mathrm{l})$ were tested on Pseudomonas Selective Agar. King's "A" agar was used as the non-selective control. The viable count of three of four cultures, which gave a minimum inhibitory concentration of $16 \mathrm{mg} / \mathrm{l}$ for Irgasan, was reduced by about 10 fold on Pseudomonas Isolation Agar, and four cultures with a minimum inhibitory concentration of $8 \mathrm{mg} / \mathrm{l}$ or below were completely inhibited by Pseudomonas Isolation Agar. Of the 10 cultures tested on Pseudomonas Selective Agar, four failed to grow and they were all sensitive to cetrimide at the concentration in the proprietary medium; three of these cultures were also sensitive to nalidixic acid. The viable count of two cultures, which were sensitive to nalidixic acid (minimum inhibitory concentration $8 \mathrm{mg} / \mathrm{l}$ ) but fully resistant to cetrimide (minimum inhibitory concentration $1024 \mathrm{mg} / \mathrm{l}$ ), was reduced by 1-log on Pseudomonas Selective Agar. In contrast, the culture that was sensitive to cetrimide (minimum inhibitory concentration $64 \mathrm{mg} / \mathrm{l}$ ) but resistant to nalidixic acid $(16 \mathrm{mg} / \mathrm{l})$ was completely inhibited by the medium.

\section{Discussion}

Selective media, especially cetrimide agar, are often used to isolate and identify $P$ aeruginosa in a single step. A recent study concluded that a selective technique using cetrimide agar permitted the reliable quantitation of $P$ aeruginosa in the liquefied sputum of patients with cystic fibrosis. ${ }^{6}$ There was considerable variation in the viable count of $P$ aeruginosa from patients in that sudy $\left(4 \times 10^{4}-8 \times 10^{8}\right.$ colony forming units/g of sputum), and this variation may have been due to the sensitivity of cultures to the selective agent.

Some cultures of $\boldsymbol{P}$ aeruginosa from cystic fibrosis show increased sensitivity to cell wall antibiotics ${ }^{7}$ and give minimum inhibitory concentration values of eight fold or less than the median for a particular antibiotic. Our data suggest that increased sensitivity of cystic fibrosis cultures also extends to the compounds Irgasan, cetrimide, and nalidixic acid. Assuming that our series of cultures is representative, then about one fifth of Paeruginosa in cystic fibrosis would be totally or partially inhibited by one or other of the two selective media. In contrast, cultures from other sources, including respiratory isolates, do not exhibit such sensitivity to the selective agents.

El-Nima described results which suggested that cetrimide acts synergistically with ampicillin and other antibiotics against $P$ aeruginosa, probably by increasing the permeability of the bacterial cell. ${ }^{8} \mathrm{We}$ did not investigate the synergism between cetrimide and nalidixic acid against cystic fibrosis cultures, but if it does occur then the proportion of the isolates inhibited by Pseudomonas selective agar may well be increased.

We recommend that the sputum from patients with cystic fibrosis should be cultured on both selective and non-selective media to maximise the isolation of $P$ aeruginosa.

We thank Drs JC Batten and ME Hodson of the Brompton Hospital, London, for the specimens of sputum from their patients with cystic fibrosis.

\section{References}

${ }^{1}$ Penketh ARL, Pitt TL, Roberts D, Hodson ME, Batten JC. The relationship of phenotype changes in Pseudomonas aeruginosa to the clinical condition of patients with cystic fibrosis. Am Rev Resp Dis 1983;127:605-8.

${ }^{2}$ King GO, Ward MK, Raney DE. Two simple media for the demonstration of pyocyanin and fluorescein. $J$ Lab Clin Med 1954; 44:301-5.

${ }^{3}$ Rawlins GA. Liquefaction of sputum for bacteriological examination. Lancet 1953;ii:538-9.

${ }^{4}$ King A, Warren C, Shannon K, Phillips I. The in-vitro activity of cefotaxime compared with that of cefuroxime and cefoxitin. Antimicrob Agents Chemother 1980;6:479-94.

${ }^{5}$ Miles AA, Misra SS, Irwin JO. The estimation of the bactericidal power of blood. J Hyg 1938;38:993-5.

${ }^{6}$ Wong K, Roberts MC, Owens L, Fife M, Smith AL. Selective media for the quantitation of bacteria in cystic fibrosis sputum. J Med Microbiol 1984;17:113-9.

${ }^{7}$ Irvin RT, Govan JRW, Fyfe JAM, Costerton JW. Heterogeneity of antibiotic resistance in mucoid isolates of Pseudomonas aeruginosa obtained from cystic fibrosis patients: role of outer membrane proteins. Antimicrob Agents Chemother 1981;19:1056-63.

${ }^{8}$ El-Nima EI. The synergism between cetrimide and antibiotics against Pseudomonas aeruginosa. Zentralbl Bakteriol Mikrobiol Hyg [A] 1984;258:120-7.

Requests for reprints to: Dr TL Pitt, Division of Hospital Infection, Central Public Health Laboratory, 61 Colindale Avenue, London NW9 5HT, England. 